\title{
Standard Value of Lower Extremity Muscle Strength of 8 Years Old Children and Its Correlation with Body Weight and Height
}

\author{
Sarifitri FH Hutagalung, Ferial Hadipoetro Idris, Luh K Wahyuni \\ Department of Physical Medicine and Rehabilitation, University of Indonesia, Cipto Mangunkusumo \\ Hospital, Jakarta.
}

\begin{abstract}
Objectives: to know the standard value of lower extremity muscle strength of eight year old children and furthermore to explore the correlation of the muscle strength and body height and weight.

Methods: The study design is cross sectional. The target is eight year old children in public elementary school in Jakarta Pusat. The subjects' characteristics are normal nutritional state, and no neurological nor musculoskeletal disorders. Sampling was done by cluster randomization to determine the location and simple randomization on site to determine subjects. There were 171 boys and 180 girls in this tudy. Independent variables are age, sex, body weight, body height and nutritional state that was determine with Z-score of body mass index. Dependent variables are lower extremity muscle strength that classify as torque. This study used hand-held dynamometer for muscle strength measurement. Statistical analysis was done with descriptive statistic and Pearson and Spearman correlation test.

Results: Standard values of eight year old boy's lower extremity muscle strength are: right hip flexor 21.86 $\mathrm{Nm}$ (SD 3.40), left hip flexor 19.64 Nm (SD 3.19), right hip extensor 17.05 Nm (SD 3.66), left hip extensor 16.08 Nm (SD 3.56), right knee extensor 18.19 Nm (SD 3.60), left knee extensor 16.09 Nm (SD 3.55), right knee flexor 15.18 Nm (SD 4.23), left knee flexor $14.48 \mathrm{Nm}$ (SD 3.97), right ankle dorsiflexor $6.58 \mathrm{Nm}$ (SD 1.53), left ankle dorsiflexor $6.05 \mathrm{Nm}$ (SD 1.42), right ankle plantarflexor $10.08 \mathrm{Nm}$ (SD 1.69), left ankle plantarflexor $9.13 \mathrm{Nm}$ (SD 1.90).

Standard values of eight year old girl's lower extremity muscle strength are: right hip flexor $21.60 \mathrm{Nm}$ (SD 3.62), left hip flexor 19.62 Nm (SD 3.37), right hip extensor 16.66 Nm (SD 4.06), left hip extensor $15.81 \mathrm{Nm}$ (SD 3.94), right knee extensor 17.43 Nm (SD 3.79), left knee extensor 15.20 Nm (SD 3.38), right knee flexor 14.61 Nm (SD 4.28), left knee flexor 13.51 Nm (SD 4.00), right ankle dorsiflexor 6.34 Nm (SD 1.45), left ankle dorsiflexor $5.97 \mathrm{Nm}$ (SD 1.52), right ankle plantarflexor 9.55 Nm (SD 1.98), left ankle plantarflexor 8.69 Nm (SD 1.83). The boy's lower extremity muscle strength are stronger than the girl's in left knee extensor, left knee flexor, right ankle plantarflexor and left ankle plantarflexor. The boy's muscle strength are moderately correlated to body height except for right hip extensor, left hip extensor and right ankle dorsiflexor that weakly correlated. The boy's muscle strength are moderately correlated to body weight except for left hip extensor that weakly correlated. The girl's muscle strength are moderately correlated to body height. The girl's muscle strength are moderately correlated to body weight except for left hip flexor and left hip extensor that weakly correlated.

Conclusions: The muscle strength pattern of boys and girls is similar; the strongest are right hip flexor and the weakest are left ankle dorsiflexor.
\end{abstract}

Keywords: Muscle strength, standard values of eight year old children, torque, hand-held dynamometer 


\section{INTRODUCTION}

Muscle is one of the important system in children's activity daily living and development. It also plays main role in their growth and development. The problem in children's muscle usually influence their movement pattern. ${ }^{1}$ Therefore it is needed to analyze muscle's function and performance.

Children muscle test is usually done by Manual Muscle Testing and inspection during activity daily living. ${ }^{1,2}$ This is a quantitative measurement and can not give exact amount of muscle strength. ${ }^{1,2}$ MMT has low inter rater reliability and low sensitivity especially in fair and normal grade. ${ }^{5,6}$

Children have different muscle dimension and weight during children growth and development . Raise on body weight and height means development of their muscle strength and performance. There is not enough data how the growth and development can influence the muscle performance. Changing in extremity length will change the lever arm length and it means changing in muscle torque. ${ }^{3}$ Changing in muscle diameter will change the center of mass of the muscle and it will also influence the torque that produce.

We need a sensitive and reliable and reproduceable instrument to measure the children muscle strength. We choose hand held dynamometer considering its lightweight so it easy to be carry and to cover many respondents. ${ }^{7}$ It is also easy to be use, just needed short time measurement for every respondent.

Hand held dynamometer has widely use in muscle strength measurement for normal and disabled children and adults. ${ }^{7,8}$ muscle

Received in March 2013 and accepted for published in April 2013.

Correspondence address: Sarifitri FH Hutagalung, Jl. Belibis No.7, Kompleks Bumi Makmur, Pondok gede, Bekasi 17413, Indonesia. Email: fitridedi@yahoo.co.id strength was measured by the muscle torque. It is done by multiply the muscle force (showed in dynamometer) and the distance of dynamometer placement to the centre of joint. ${ }^{11}$

There is no standard value of muscle strength among normal children in Indonesia. We also do not have standard procedure for muscle strength measurement for children. It is needed for screening of muscle weakness and for rehabilitation program evaluation. One of the aims of this study is to get to know the standard value of lower extremity muscle strength. We choose the eight year old children considering that in that age children already developed enough and easy to understand the command and for reproduce the procedure. We also explore the correlation of body weight and height to muscle strength to analyze the children growth influence.

\section{METHODS}

The population is children in 10 public elementary school in Jakarta Pusat. This study had an Ethical Clearance from Ethic research committee of Faculty of Medicine of University of Indonesia. The data were taken from February to March 2008. The study design was cross sectional.

Subjects must meet criterias as follows: children of eight year old in normal nutritional state and had no neuromuscular problems. They also asked for parent's permission to joint the study. The children will be excluded if they are had history of neuromuscular disease, cardiovascular problem, had infection or had pain on the lower extremity.

The procedure was conducted by the investigator in one day for every school. The children were measured for their body height and weight. The nutritional state will be determined by NutStat from Epi Info program (based n 2002 
CDC-WHO). They were also examined for their allignment, muscle tone and range of motion. Muscle strength measurement was done in specific manner according to the muscle group that tested. The length of lever arm is measured from the dynamometer placement to the centere of the joint tested. The muscle strength was expressed in muscle torque (Newton meter).
Data are expressed as the mean, median and standard deviation of torque (result of most powerful muscle force multiply to ler arm length). We used Pearson correlation to know relationship between two variables.

\section{RESULTS}

There were 171 boys and 180 girls included in this study.

Table 1. Characteristics of Boy Subjects

\begin{tabular}{lcccc}
\hline & Mean & $\begin{array}{c}\text { Standard Deviation } \\
\text { (SD) }\end{array}$ & Minimum & Maximum \\
\hline Age (months) & 101.04 & 3.81 & 96 & 107 \\
Body weight (kg) & 25.92 & 5.74 & 17.4 & 53.20 \\
Body height $(\mathrm{cm})$ & 125.88 & 6.41 & 110.00 & 146.60 \\
Boy Mass Indeks(kg/ & 16.26 & 2.60 & 13.06 & 25.25 \\
$\mathrm{~cm}^{2}$ ) & & & & \\
Z-score of BMl & -0.14 & 1.16 & -2 & 2 \\
\hline
\end{tabular}

Table 2. Characteristics of Girls Subjects

\begin{tabular}{lcccc}
\hline & Mean & SD & Minimum & Maximum \\
\hline Age (months) & 101.09 & 3.79 & 96 & 107 \\
Body weight $(\mathrm{kg})$ & 25.67 & 6.09 & 16.90 & 48.40 \\
Body height $(\mathrm{cm})$ & 125.29 & 7.36 & 107.50 & 148.00 \\
Boy Mass Indeks $\left(\mathrm{kg} / \mathrm{cm}^{2}\right)$ & 16.20 & 2.46 & 12.24 & 24.20 \\
Z-score of BMI & -0.18 & 1.06 & -1.96 & 2 \\
\hline
\end{tabular}

Mean of standard value of lower extremity muscle strength in eight year old boys are: right hip flexor 21.86 Nm (SD 3.40), left hip flexor $19.64 \mathrm{Nm}$ (SD 3.19), right hip extensor 17.05 Nm (SD 3.66), left hip extensor $16.08 \mathrm{Nm}$ (SD 3.56), right knee extensor $18.19 \mathrm{Nm}$ (SD 3.60), left knee extensor 16.09 Nm (SD 3.55), right knee flexor $15.18 \mathrm{Nm}$ (SD 4.23), left knee flexor $14.48 \mathrm{Nm}$ (SD 3.97), right ankle dorsiflexor $6.58 \mathrm{Nm}$ (SD 1.53), left ankle dorsiflexor 6.05 $\mathrm{Nm}$ (SD 1.42), right ankle plantarflexor 10.08 Nm (SD 1.69), left ankle plantarflexor $9.13 \mathrm{Nm}$ (SD 1.90).

Mean of standard value of lower extremity muscle strength in eight year old girls are: right hip flexor $21.60 \mathrm{Nm}$ (SD 3.62), left hip flexor 19.62 Nm (SD 3.37), right hip extensor 16.66 Nm (SD 4.06), left hip extensor 15.81 Nm (SD 3.94), right knee extensor $17.43 \mathrm{Nm}$ (SD 3.79), left knee extensor $15.20 \mathrm{Nm}$ (SD 3.38), right knee flexor $14.61 \mathrm{Nm}$ (SD 4.28), left knee flexor $13.51 \mathrm{Nm}$ (SD 4.00), right ankle dorsiflexor $6.34 \mathrm{Nm}$ (SD 1.45), left ankle dorsiflexor 5.97 $\mathrm{Nm}$ (SD 1.52), right ankle plantarflexor 9.55 $\mathrm{Nm}$ (SD 1.98), left ankle plantarflexor $8.69 \mathrm{Nm}$ (SD 1.83).

The boys usually have stronger muscles than the girls, the significant difference can be seen in four muscle groups; left knee extensors, left knee flexors, right plantarflexors and left 
plantarflexors. The muscle strength pattern in boys and girls are similar. The most powerful muscles in lower extremity are right hip flexor and the weakest are left dorsiflexors.

There is moderate correlation between lower extremity muscle strength and body weight in boys, except for the hip extensors (Table 3). There are also moderate correlation between lower extremity muscle strength and body height in boys, except for the right and left hip extensors and right ankle plantar flexors (Table 4).

Table 3. Correlation Between Muscle Strength and Body Weight in Boys

\begin{tabular}{cc}
\hline Muscle & p \\
\hline Weight & 1.000
\end{tabular}

FLPAKA

FLPAKA : right hip flexor, FLPAKI : left hip flexor, EXTPAKA : right hip extensor, EXTPAKI : left hip extensor, EXTLUKA : right knee extensor, EXTLUKI : left knee extensor, FLLUKA : right knee flexor, FLLUKI : left knee flexor, DOFLAKKA: right ankle dorsiflexor, DOFLAKKI : left ankle dorsiflexor, PLFLKA : right ankle plantarflexor, PLFLKI : left ankle plantarflexor 
Table 4. Correlation Between Muscle Strength and Body Height in Boys

\begin{tabular}{|c|c|}
\hline Muscle & p \\
\hline Body Height & 1.000 \\
\hline FLPAKA & .511 \\
\hline FLPAKI & .482 \\
\hline ЕХТРАКА & .379 \\
\hline EXTPAKI & .371 \\
\hline EXTLUKA & .495 \\
\hline EXTLUKI & .462 \\
\hline FLLUKA & .514 \\
\hline FLLUKI & .491 \\
\hline DOFLAKKA & .375 \\
\hline DOFLAKKI & .441 \\
\hline PLFLKA & .494 \\
\hline PLFLKI & .474 \\
\hline
\end{tabular}

Spearman's rho test

FLPAKA : right hip flexor, FLPAKI : left hip flexor, EXTPAKA : right hip extensor, EXTPAKI : left hip extensor, EXTLUKA : right knee extensor, EXTLUKI : left knee extensor, FLLUKA : right knee flexor, FLLUKI : left knee flexor, DOFLAKKA: right ankle dorsiflexor, DOFLAKKI : left ankle dorsiflexor, PLFLKA : right ankle plantarflexor, PLFLKI : left ankle plantarflexor

There are moderate correlation between lower extremity muscle strength and body weight in girls, except for the left hip flexors and left hip extensors (Table 5). All of the lower extremity muscle group have moderate correlation with body height in girls (Table 6). 
Table. 5 Correlation Between Muscle Strength and Body Weight in Girls

\begin{tabular}{|c|c|}
\hline Muscle & p \\
\hline Body Weight & 1.000 \\
\hline FLPAKA & .428 \\
\hline FLPAKI & .384 \\
\hline EXTPAKA & .413 \\
\hline EXTPAKI & .387 \\
\hline EXTLUKA & .441 \\
\hline EXTLUKI & .462 \\
\hline FLLUKA & .609 \\
\hline FLLUKI & .581 \\
\hline DOFLAKKA & .459 \\
\hline DOFLAKKI & .437 \\
\hline PLFLKA & .506 \\
\hline PLFLKI & .472 \\
\hline
\end{tabular}

Spearman's rho test

FLPAKA : right hip flexor, FLPAKI : left hip flexor, EXTPAKA : right hip extensor, EXTPAKI : left hip extensor, EXTLUKA : right knee extensor, EXTLUKI : left knee extensor, FLLUKA : right knee flexor, FLLUKI : left knee flexor, DOFLAKKA: right ankle dorsiflexor, DOFLAKKI : left ankle dorsiflexor, PLFLKA : right ankle plantarflexor, PLFLKI : left ankle plantarflexor 
Table 6. Correlation Between Muscle Strength and Body Height in Girls

\begin{tabular}{cc}
\hline Muscle & p \\
\hline Body Height & 1.000 \\
FLPAKA & .519 \\
FLPAKI & .532 \\
EXTPAKA & .473 \\
EXTPAKI & .475 \\
EXTLUKA & .533 \\
EXTLUKI & .556 \\
FLLUKA & .614 \\
PLLFLKA & .477 \\
FLLUKI & .468 \\
DOFLAKKA & .465 \\
\hline
\end{tabular}

Spearman's rho test

FLPAKA : right hip flexor, FLPAKI : left hip flexor, EXTPAKA : right hip extensor, EXTPAKI : left hip extensor, EXTLUKA : right knee extensor, EXTLUKI : left knee extensor, FLLUKA : right knee flexor, FLLUKI : left knee flexor, DOFLAKKA: right ankle dorsiflexor, DOFLAKKI : left ankle dorsiflexor, PLFLKA : right ankle plantarflexor, PLFLKI : left ankle plantarflexor

\section{DISCUSSION}

There is no significance differences between the boys and the girls subjects' characteristics included the body weight, body height, body mass index and Z-score of nutritional state. It is a realistic fact considering that there is no significance difference of body characteristics between boys and girls on age of 8 . The difference will be obviously showed after the puberty which is age 9-11 years old on girls and 
13 years old on boys. ${ }^{12}$

This study showed that on hip joint, flexor muscles are stronger than extensors, while on knee joint, extensors muscles are stronger than flexors. On ankles, plantarflexor muscles are stronger than dorsiflexors. These results are similar to studies from Andrews et al, ${ }^{26}$ Benakker et al, ${ }^{21}$ Dunn et al, ${ }^{28}$ Eek Nystrom et $\mathrm{al},{ }^{2}$ Hill et al, ${ }^{29}$ and Jung et al. ${ }^{30}$

The most powerful muscles in boys and girls are right hip flexors. It is different than the Eek Nystrom et $\mathrm{al}^{2}$ that found the right knee extensors are the most powerful muscles on children in Sweden. The difference might be connected to the physical activity and social activity on children in Indonesia and in Sweden. Another factors are the body height, body weight and nutritional state between these two countries.

The weakest muscles on boys are left ankle dorsiflexors. It is same result as seen on Eek Nystrom et $\mathrm{al}^{2}$ and Beenakker et $\mathrm{al}^{21}$ study . There is different result showed in Andrews et $\mathrm{al}^{26}$ study that showed knee flexors are the weakest. The muscles strength pattern that we found in this study is similar to the Simoneau study ${ }^{34}$ of "joint movement and internal torque pattern during gait" on 2002.

The boys' muscles mostly have moderate correlation to body weight $(0,4<\mathrm{r}<0,8)$. The exception is only in left hip extensor that have weak correlation to body weight. This is similar to results on Andrews et $\mathrm{al}^{26}$ study. Different results showed on Beenakker et $\mathrm{al}^{21}$, Samson et $\mathrm{al}^{33}$ and Eek Nystrom et $\mathrm{al}^{2}$ that showed strong correlation between muscle strength and bodyheight

The boys' muscles mostly have moderate correlation to body height $(0,4<\mathrm{r}<0,8)$. The exception are in right and left hip extensor, and right ankle dorsiflexor that have weak correlation to body height. This result is similar to Beenakker et $\mathrm{a}^{21}$ for 8 year old children and Andrews et $\mathrm{al}^{26}$ on 50-79 y.o adult. Different result showed on Samson et $\mathrm{al}^{33}$ that showed there is strong correlation between muscle strength and body height on 20-55 y.o man.

The girls' muscles mostly have moderate correlation to body weight $(0,4<\mathrm{r}<0,8)$. The exception are in left hip flexor and left hip extensor that have weak correlation to body weight. Different results showed on Beenakker et $\mathrm{al}^{21}{ }^{21}$ Eek Nystrom et $\mathrm{al}^{2}$ and Samsons et $\mathrm{al}^{33}$ study that showed there is strong correlation betweeen girl's muscle strength and body.

All of the girls' muscles have moderate correlation to body weight $(0,4<\mathrm{r}<0,8)$. The similar results showed on Beenakker et al, ${ }^{21}$ Samson et $\mathrm{al}^{33}$ and Andrews et al. ${ }^{26}$ There is strong correlation between muscle strength and body height in adult.

\section{CONCLUSIONS}

The muscle strength pattern of boys and girls is similar; the strongest are right hip flexor and the weakest are left ankle dorsiflexor.

\section{REFERENCES}

1. Jones K, Barker K. Human Movement Explained. Oxford: ButterworthHeinemann; 1996. p.196-223.

2. Eek Nystrom M, Korksmark AK, Beckung E. Isometric Muscle Torque in Children 5 to 15 Years of Age: Normative Data. Arch Phys Med Rehabil.19 87; 8: 1091-9.

3. Hinderer KA, Hinderer SR. Muscle Strength Development and Assessment in Children and Adolescent. In: HarmsRingdahl K, editor. Muscle Strength. Edinburgh: Churchil Livingstone; 1993. p. 93-140. 
4. Escolar DM, Henricson EK, Mayhew J. Clinical Evaluator Reliability for Quantitive and Manual Muscle Testing Measures of Strength in Children. Muscle Nerve. 2001;24: 787-93.

5. Schwartz ME, Cohen ME, Herbison GJ. Relationship Between Two Measures of Upper Extremity Strength Manual Test Compared to Handheld Myometry. Arch Phys Med Rehabil. 1992;73: 1063-8.

6. Aitkens S, Lord J, Bernauer E, Fowler Jr WM, Lieberman JS, Berck P. Relationship of manual muscle testing to objective strength measurements. Muscle Nerve. 1989;12: 173-7.

7. Stratford PW, Balsor BE. A Comparison of Make and Break Test Using a Handheld Dynamometry and the Kin-Com. J Orthop Sports Phys Ter. 1994;19: 28-32.

8. Taylor NF, Dodd KJ, Graham HK. Test-Retest Reliability of Hand-held Dynamometry Testing in Young People with Cerebral Palsy. Arch Phys Med Rehabil. 2004;85: 77-80.

9. Harms-Ringdahl K, Ekholm J. Biomechanical Aspect of Exercise. In: Harms-Ringdahl, editor. Muscle Strength. Edinburgh: Churchill Livingstone;1993. p.37-60.

10. Krause DA, Schlagel SJ, Stember BM, Zoeteway JE, Hollman JH. Influence of Lever Arm and Stabilization on Measures of Hip Abduction and Adduction Torque Obtained by Hand-held Dynamometry. Arch Phys Med Rehabil. 2007;88: 37-42.

11. Bohannon RW. Muscle Strength in Patients with Brain Lessions, Measurement and Implication. In: Harms-Ringdahl, Editor. Muscle Strength. Edinburgh: Churchill Livingstone; 1993. p.187-225.

12. Gallahue DL. Understanding Motor development in Children. New York: John
Wiley \& Sons. Inc; 1982. p. 40-130.

13. Ktzmarzyk PT. Physical Activity and Chronic Diseases. In: ACSM'S Resources Manual for Guidelines for Exercise Testing and Prescription, $5^{\text {th }}$ ed. Philadelphia: Lippincott Williams \& Wilkins; 2006. p.123-33.

14. Jones MA, Stratton G. Muscle function Assessment in Children. Acta Paediatrica. 2000;89: 753-61.

15. Cole TM, Barry DT, Tobis JS. Measurement of Musculoskeletal Function. In: Kottke FJ, Lehmann JF editors. Krusen's handbook of Physical Medicine and Rehabilitation. $4^{\text {th }}$ ed. Philadelphia: WB Saunders; 1990. p.2071.

16. Hislop HJ, Montgomery J. Daniels and Worthingham's Muscle Testing. Philadelphia: W B Saunders; 2002. p.112.

17. de Lateur BJ, Lehmann JF. Therapeutic Exercise to Develop Strength and Endurance. In: Kottke FJ, Lehmann JF, editors. Krusen's Handbook of Physical Medicine and Rehabilitation. Philadelphia: WB Saunders; 1990. p.480-519.

18. Wilder P. Muscle Development and Function. In: Cech,Martin,editors. Functional Movement Development Across the Life Span. Philadelphia: WB Saunders; 1995. p.137- 58.

19. Lieberman JS, Pugliese GN, Strauss NE. Skeletal Muscle: Structure, Chemistry and Function. In: Downey \& Darling's Physiological Basis of Rehabilitation Medicine. Boston: ButterworthHeinemann; 2001. p. 67-80.

20. Powers SK, Howley ET. Skeletal Muscle, Structure and Function. In: Powers SK, Howley ET, editors. Exercise Physiology. New York: Mc Graw Hill; 2001. p.129-56. 
21. Beenakker EA, van der Hoeven JH, Fock JM, Maurits NM. Reference Values of Maximum Isometric Force Obtained in 270 Children Aged 4-16 Years by Handheld Dynamometry. Neuromuscul Disord. 2001;11: 441-6.

22. NASPE Physical Activity Guidelines 2004. Available from: www.cdc.gov.com.

23. Bohannon RW. Muscle Strength Testing with Handheld Dinamometry. In: Amundsen LR, editor. Muscle Strength Testing. Instrumented and non Instrumented Systems. New York: Churchill Livingstone; 1990. p.89-122.

24. United States Department of Health and Human Services, Centers for Disease Control and Prevention. Epi Info. Available from: http://www.cdc.gov.EpiInfo/epiinfo. htm.

25. Madiyono B, Moeslichan Mz, Sastroasmoro S, Budiman I, Purwanto SH. Perkiraan Besar Sampel. In: Sastroasmoro $\mathrm{S}$, Ismael S, editors. Dasar-Dasar Metodologi Penelitian Klinis. Jakarta: CV Sagung Seto; 2002. p.259-87.

26. Andrews AW, Thomas MW, Bohannon RW. Normative Values for Isometric Muscle Force Measurements Obtained with Handheld Dynamometers. Phys Ther. 1996;76: 248-59.

27. Phillips BA, Lo SK, Mastaglia FL. Muscle Force Measured Using Break Testing With a Handheld Dynamometer in Normal Subjects Aged 20-69 Years. Arch Phys Med Rehabil. 2000; 81 : 653-61.

28. Dunn J C, Iversen MD. Interrater reliability of Knee Muscle Forces Obtained by Handheld Dynamometer from Elderly Subjects with degenerative Back Pain. Journal of Geriatric Physical Therapy. 2003; 26: 239.
29. Hill C, Croce R, Miller J. Muscle Torque Relationship between Handheld Dynamometry and Isokinetic Measurement in Children Ages 9-11 Years. The Journal of Strength and Conditioning Research. 1996; 10: 77-82.

30. Jung SH, Cook SB, Ordway NR, PloutzSnyder LL. Reliability and validity of Handheld Dynamometer To Assess Knee and Ankle Strength in An Older Adult Population. Med Sci Sports Exerc. 2007; 39: S249.

31. Merlini ML, Mazzone ES, Solari AS, Morandi L. Reliability of Handheld Dynamometry in Spinal Muscular Atrophy. Muscle Nerve. 2002; 26: 64-70.

32. Barber-Westin SD, Noyes FR, Galloway M. Jump-Land Characteristics and Muscle Length Development in Young Athletes. A gender Comparison of 1140 Athletes 9 to 17 Years of Age. The Am J Sports Med. 2006;34: 375-84.

33. Samson MM, Meeuwsen IB, Crowe A, Dessens JA, Duursma SA, Verhaar $\mathrm{Hj}$. Relationship between Physical Performance Measures, Age, Height and Body Weight in Healthy Adult. Age Ageing. 2000; 29: 235-42.

34. Simoneau GG. Kinesiology of Walking. In: Neumann DA, editor. Kinesiology of The Musculoskeletal System Foundation for Physical Rehabilitation. St. Louis: Mosby; 2002. p.523-69.

35.Rauch F, Neu CM, Wassmer G, Beck B, Rieger-Wettengel G, Rietschel E, Manz F, Schoenau E.

Muscle Analysis by Measurement of Maximal Isometric Grip Force: New Reference Data and Clinical Applications in Pediatrics. Pediatr Res. 2002;51:505-10. 